\title{
О.И. Колесникова
}

\section{ПЕРСУАЗИВНЫЙ ТЕКСТ ИЗДАТЕЛЬСКОЙ АННОТАЦИИ: ЛИНГВОКУЛЬТУРНЫЙ АСПЕКТ}

\begin{abstract}
Аннотация. $B$ статье с позиций лингвокультурного подхода рассматривается текст как средство продвижения литературно-художественной книги в медиа. Представлены результаты анализа персуазивных (убеждающих) текстов аннотаций, размещенных на спечиализированных сайтах. Выявлены лингвокультуремы, формирующие в тексте ценностные смысль и стимулирующие читательский интерес к книжной новинке. Раскрываются способы создания стилистического эффекта, в которых реализуются прагматико-эстетические функиии культурем.
\end{abstract}

Ключевые слова: издательская аннотачия, персуазивный текст, лингвокультурема, стилистический эффект, прагматико-эстетические функции.

В настоящее время важным культурным событием в литературной жизни стала книга не как эстетический феномен, а как «издательскирыночный продукт» [1. С. 48]. Действительно, современный медиатекст на рекомендательных и коммерческих сайтах в Рунете ${ }^{1}$, предлагающий книжную новинку читателям, можно квалифицировать и как литературный, и как «продвигающий» текст, рассматривать его не только как культурообразующий фактор чтения, но и в качестве единицы маркетингового дискурса ${ }^{2}$.

Рекламу постмодернистской эпохи, по мнению специалистов [3], отличает 1) нацеленность потребителей на минимальную скорость получения информации (выгода покупателя), 2) нацеленность рекла-

1 Медиаисточники исследования: раздел «Книги» на сайте «Books.ru», peкламный каталог «С книгой в руках» на сайте «Озон.ру», сайты «Лабиринт.ру», «Читай-город», «Литлавка», «Книжный Клуб “Клуб Семейного Досуга”» и др.; сайты книжных торговых организаций («Библио-Глобус», «Московский дом книги» и др.); сайты издательств «Эксмо», «АдМаргинемПресс», «ОлмаМедиаГрупп», «РИПОЛ классик», «Азбука-Аттикус».

2 Понятие и специфика продвигающего текста, в том числе маркеры жанра рекомендательной научной аннотации,рассмотрены в работе [2]. 
модателей (выгода «продавца») - на брендирование продукции (в контексте данной статьи - превращение книги в товарный знак издательства). Можно предположить, что для решения данных задач, особенно в сфере продвижения художественной литературы, и прозы в частности, требуется особый материал словесности. Такой материал, обладающий, по нашему мнению, как прагматической, так и эстетической функциями, должен убедить адресата в тех или иных качествах презентуемого объекта, вызвав стилистический эффект. Способы достижения эффекта изучаются не только в стилистике, но и в новом интегративном направлении - маркетинговой лингвистике, понятийный аппарат которой сейчас активно разрабатывается (см., например, [4]). В зарубежных научных работах в последнее время уделяется много внимания языку маркетинга [5-7 и др.]. Наряду с исследованием (преимущественно в рамках потребительской психологии) таких свойств «продвигающего текста», как доступность [8], привлекательность [9], эмоциональное заражение [10], изучаются эффективные способы убеждения, определяемые «природой» товара или сферой услуг.

В книгоиздательской, как и любой маркетинговой сфере, задачу «продвигать» реализуют специфические персуазивные (обладающие убеждающим потенциалом) средства. Так как книга относится к культурным ценностям общества ${ }^{1}$, ее рекламная презентация, несомненно, требует особой коммуникативно-речевой деятельности. Прежде всего необходимо назвать жанрообразующий фактор: в медиасфере книжная продукция в коммерческом формате предлагается посредством текстов издательских аннотаций, кратких рецензий и описаний. Исследователи языка рекламы считают, что одной из речевых функций позиционирования продукта является «обоснование оценки с опорой на ценности потребительского общества» [12. С. 25]. Литературнохудожественное издание ориентировано на другую опору маркетинговой стратегии, основанную на традиционном ценностном потенциале: духовной потребности в чтении, интересе к художественному постижению жизни человека и общества.

${ }^{1}$ Следует подчеркнуть, что издательский бизнес и книготорговля по закону РФ отнесены к творческой индустрии, производящей и представляющей на рынке культурные продукты [11]. 
Лингвокультурный подход предполагает приоритетность вербальной составляющей текста в данном сегменте маркетинга. Задача автора текста аннотации - найти такие способы, которые смогут убедить читателя в том, что именно его запросы и ожидания в сфере чтения как полезного или приятного проведения времени будут оправданы. Н.А. Рубакин считал «рекомендацию» самой сутью книжного дела и в связи с этим придавал огромное значение слову как возбудителю психических переживаний [13]. Основатель библиопсихологии выражал серьезное опасение перед теми последствиями, которые возможны, если тот или иной читатель в результате неумелых действий «книжников» возьмет в руки «не свою» книгу. Помочь читателю найти свою книгу - назначение аннотации. По мнению многих исследователей проблемы продвижения книжной продукции, особенно оживленно обсуждающейся в первой четверти XXI в. (Н.В. Авериной [14], А.Б. Берштадта [15], М.Н. Вишняковой [16], А.Н. Моревой [17], Д.М.Переднего [18]), «классическая» издательская аннотация в рекламной интерпретации приобрела новые черты, стала актуальным жанром рекламы книги. Цель любого рекламного текста - позиционирование тех главных свойств объекта, на которых «должен быть сделан рекламный акцент» [19. С. 59].

Рекламную издательскую аннотацию можно определить как такой медийный жанр, который служит информационно-рекламной цели, реализуемой в краткой характеристике произведения, темати$\kappa и$, значения и места в литературной жизни, основных художественных особенностей, представляя их в наиболее привлекательном для читателя виде. Текст аннотации, с одной стороны, это маркетинговый инструмент, с другой - продукт творческого мышления, решающий задачу заинтересовать читателя, показать ему специфику объекта. Творческое мышление, по данным исследователей маркетинга, сходно с критическим мышлением. Однако если в процессе работы критического мышления те или иные способы выражения рекламной цели исключаются в пользу «лучшего» варианта, то метафорические мыслительные процессы творческого мышления направлены на поиск оригинального варианта [20. С. 10].

«Профессиональные» рекламные тексты о книгах создаются редакторами книжных рубрик журналов, литературными обозревателями, писателями, журналистами. Автор аннотации, распространяемой 
в медиа, является «the cultural intermediaries reader» ${ }^{1}$, т.е. посредником между потребителем (читателем) и товаром (книгой). Он выполняет культурную миссию (которая состоит, по мнению П. Бурдье, в производстве ценности книги агентом, «продуцирующим “веру в творческую силу автора"» [22]).

Как показал анализ медиаресурсов, посредник (агент) создает в тексте аннотации «поле культуры», выступая в определённой «литературной маске». Он не наблюдатель или консультант, а знаток, ценитель, любитель литературы. Сущность коммуникативно-речевой деятельности «культурного посредника» - презентовать автора произведения в образе человека-бренда; эмоционально передать краткое содержание рекламируемой книги; увлекательно рассказать о событиях, послуживших толчком к развитию сюжета; информировать об отношении критиков к произведению или его месте в литературе. Для этих целей адресант рекламы находит такие средства языка, которые приводят адресата к убеждению в ценности предлагаемой книги и таланте писателя.

Рассматривая языковой план издательской аннотации в лингвокультурном аспекте, можно обнаружить, что персуазивность - свойство так называемых культурных единиц текста. Это единицы, которые должны, во-первых, быть адекватны виду своего дискурса и, вовторых, подчиняться прагматическим функциям, характерным для той или иной коммуникативной ситуации [23]. Результаты анализа текстов рекомендательных аннотаций новинок художественной прозы позволяют говорить о том, что адекватность дискурсу рекламы в этом сегменте обеспечивается «лингвокультуремами» - эстетически значимыми носителями персуазивности: они организуют «поле притяжения» читательского внимания словесными манифестациями неповторимости или художественной ценности книги, а также увлекательности самого чтения произведения литературы как объекта маркетингового предложения. Культурные единицы аннотаций выполняют свою прагматическую функцию убеждения адресата в ценности предлагаемого объекта на двух уровнях текста. На первом, фактологическом, уровне в лингвокультуремах передается информация о месте рекла-

${ }^{1}$ Концепция посредничества, включая розничную торговлю книгами, представлена, в частности, в работе [21]. 
мируемой книги в мире литературы, ее популярности у читателей, о сюжете, а также об авторе произведения, его жизни, судьбе, творчестве. На интерпретационном уровне представляется ключевая идея произведения, его язык и стиль, получает одобрительные характеристик адресат, формируется предвосхищение удовольствие от чтения рекламируемой книги.

Лингвокультуремы прагматически нацелены на «творческое вовлечение» широкого читателя в чтение книги на этапе знакомства с ее аннотацией. Передавая культурные смыслы и ценностную информацию на обоих уровнях персуазивного текста, они выступают в роли своеобразных сигналов эстетического способа передачи информации. Такие сигналы в креативной стилистике называют «аттракторами». Это такие словесные знаки, которые задерживают внимание адресата при чтении текста, вызывают у него нужные эмоциональные реакции и/или раџиональный вывод-следствие их интерпретации. В речевой опосредованной коммуникации аттракторы служат успешному и быстрому достижению цели культурного посредника. Поиск, или «изобретение», аттракторов всегда является результатом творческого мышления автора аннотации.

Как показал анализ медиарекламы книги на указанных сайтах, культурные единицы вводятся в текст в процессе интерпретации качеств произведения или его чтения как ценностных смыслов. Культурный контекст образуют следующие способы создания стилистического эффекта.

1. Интертекстуальные знаки, основанные на феномене прецедентного высказывания. Они характерны для персуазивной организации текста, который предлагает произведение «высокой», «элитарной» литературы. Посредством включения «чужого» текста в коммуникацию создается многоярусный, вертикальный контекст, необходимый для осознания адресатом бесспорной ценности новой книги. Рекламируемый объект может выделяться на фоне других, даже более значительных или известных произведений; например, «Ребекка»

${ }^{1}$ На наш взгляд, следует включить результаты исследований креативной стилистики в отдельный раздел маркетинговой лингвистики, так как креатемам свойственно выполнять функции аттракторов, выступающих речевыми средствами создания привлекательности рекламного сообщения [24]. 
Д. Дюморье характеризуется следующим образом: Роман, без которого не существовало бы ни "Степного волка" Германа Гессе, ни «Кэрри» Стивена Кинга (Livelib.ru). Читателю иногда предлагается сделать мысленный ход «от обратного», чтобы, например, понять, в чем уникальность писателя: Виктор Астафьев - в каком-то смысле русский «Хемингуэй наоборот». Впрочем, смысл «загадки» разъясняется в следующей фразе: Астафьев исследует источники не силь человеческой, но слабости (Эксмо).

Адресата словно «втягивают» в интеллектуальную игру, предлагая сигналами интертекстуальности «пройти» по указанному в знаках культуры «извилистому» пути интерпретации смысла. Обращение к культурно-историческим знаковым единицам для передаче рекламной информации о проблематике произведения, «ранге его значимости», авторской концепции, писательском кредо с помощью «чужого» текста создает новизну ракурса восприятия, одновременно и усложняя, и облегчая постижение ценностного смысла. Например, в аннотации книги «Два царства» Л. Петрушевской авторская идея «затейливо» представляется как своеобразный двигатель прогресса, источник движения вперед: Ведь искусство вечно, повторяет автор, и это единственный перпетуум-мобиле в нашей жизни (Лабиринт.ру).

2. Перифрастические знаки. Назначение перифраз в медиатексте - создание у адресата нужного впечатления о значимости презентуемого произведения. С учетом двух типов адресата (массового и элитарного), можно разграничить два типа перифраз. Это, с одной стороны, стереотипные метафорические перифразы, украшающие текст, т.е. используемые в декоративной функции (вершина творчества своего великого создателя, жсемчужина мировой литературы, жемчужина магического реализма и т.д.). С другой стороны, читателю с высоким уровнем эстетических запросов адресуются тексты, содержащие более сложные перифразы. В перифразе-образе перед адресатом нередко предстает создаваемая в произведении художественная картина мира: Узнаваемое и неузнаваемое мирно соседствуют на ярком гобелене Нового средневековья (о «Теллурии» В. Сорокина). Факты перифразирования, как правило, свидетельствуют о намерении автора аннотации подчеркнуть духовную миссию писателя или неординарность его творения. В этом случае перифразы подчеркивают уникальность произведения, его роль в мировом лите- 
ратурном процессе: своеобразньй антипод второй великой антиутопии $X X$ в., литературный парадокс $X X$ столетия.

Особенно часто перифрастически именуется автор книги: А. Бушков - российский Конан Дойль (ОлмаМедиаГрупп), Сабахаттин Али «турецкий Ремарк» (АдМаргинемПресс) и т.д. Являясь способом вторичной (условной) номинации, оценочная перифраза-имя адресуется преимущественно «знатокам» литературы, так как апеллирует к фоновым знаниям литературной ситуации и ее культовых фигур. Так, в двух перифрастических номинациях М. Кэртэреску в аннотации издательства «АдМаргинемПресс» - настоящая звезда современной европейской литературы и румынский Маркес - первая выполняет оценочную функцию, а вторая - функцию апелляции к знаковым именам мировой литературы для создания эффекта.

3. Смысловые аналогии также способствуют персуазивности рекламного предложения. С их помощью в читательском восприятии создаются чувственно-семантические поля. Эффект «другого измерения» возникает благодаря переводу сознания читателя в иное семантическое пространство при сравнении двух объектов. Литературное произведение в аналогиях нередко «перемещает» восприятие адресата в визуальную плоскость: Эта обаятельная и иронично-сдержанная вещь сродни хорошей примитивной, «наивной» жсиописи - на первый взгляд просто и смешно, всмотришься - умно и трогательно (Livelib.ru).

Многоплановое смысловое пространство может моделироваться в аналогиях с помощью синэстезии. Совмещение разных признаков (например, зрительных и слуховых) вызывает эффект художественной рецепции, создает условия для эстетического наслаждения PЕЧЬЮ О ПРОИЗВЕДЕНИИ, например: «Облачный атлас» подобен зеркальному лабиринту, в котором перекликаются, наслаиваясь друг на друга, шесть голосов (Эксмо). Слово в художественной литературе - ценность особого рода, и в некоторых описаниях смысловые аналогии искусно оживляют фантазию адресата, иногда вызывая физические реакции, например: Каждое слово как укол зонтиком: без травм, но чувствительно. При этом - никакого сарказма и ядовиmых замечаний (о книге Ивлине Во, там же).

4. Эмотивные знаки нацелены на пробуждение эмоциональных откликов, предвкушение приятного и / или полезного чтения. Моти- 
вацию творческого участия читателя в повествовании в процессе чтения может повысить «любая устойчивая эмоциональная связь с художественным произведением», вымышленными персонажами [25. С. 131]. Чтобы заинтриговать, ошеломить, даже шокировать адресата, в лингвокультуремах эмотивного плана акцентируются достоинства художественного произведения. Эффект возникает благодаря указанию на способность книги вызвать различные реакции - размышления: роман заставит не только ульбнуться, но и задуматься над вопросами, на которые не так просто ответить (Литлавка) или особые ощущения: книга заворажнияет, всецело завладевая вниманием читателя, и ведёт его по закоулкам человеческой души, играя c подсознанием (Livelib.ru). Персуазивный текст обещает отдых от повседневных забот: Проза в серии «Сарафанное радио»-лучший способ отвлечься с книгой в руках (ОлмаМедиаГрупп) или даже влияние на судьбу (об «Алхимике» П. Коэльо): Этот, ставший культовым, роман-притча способен изменить жсизнь своих читателей» (Livelib.ru).

5. Прагмаэстетические атрибутивы (прилагательные и наречия) актуализируют ценностный смысл, вербализуя концептуальные (сущностные) признаки книги. Позитивные характеристики, которые они транслируют адресату, позволяют рассматривать их и как особый тип эмотивных знаков. Остросюжетные книги получают следующие определения: искромётный взгляд на российскую жизнь (ОлмаМедиаГрупп); головокружнтельные события, извлечение тайных историй из ещё более тайных архивов; неожиданный эффект превращчения размеренного действия в холодящций кровь триллер (Амфора). Такого рода аттракторы выполняют прежде всего оценочноквалифицирующую функцию, выступая культурными знаками высшей степени литературного качества произведений. Одна фраза может содержать целый ряд атрибутивов, например: «мудрая», «светлая», «сильная», «драматическая», «необыкновенно талантливая», «самая острая и спорная книга» (об издании произведений Х. Мураками).

В медиатекстах с помощью атрибутивных знаков также акцентируются динамизм и неожиданность сюжетных ходов. Сюжет предстает перед адресатом потрясающе сильным; умело закрученным; полным неожиданных поворотов или набирающих обороты событиями. 
Еще одна функция атрибутивов - ассоциативно-образная, реализуемая в развёрнутой метафоре. Например, парадоксальность художественной формы романа X. Кортасара презентуется в сочетании метафоры с эпитетом: «Игра в классики» - это дикий коктейль сюрреализма и реализма, где реальность переплетается с вымыслом, а размышления медленно превращцаются в реальность (Livelib.ru).

6. Диалогизация создает у адресата рекламы книги «эффект присутствия» до непосредственного знакомства с произведением, чему способствует как прямая, так и косвенная форма диалога. Наиболее простой способ диалогизации - форма прямого обращения к потенциальному читателю. Чаще всего в ней содержится обещание «собеседнику» желаемого результата: ...вам предстоит увлекательное приключение в самое сердие Тьмын... Ничто из того, что вы читали раньше, не сравнится с самым дерзким из ужасных опьтов Стивена Кинга... (АСТ). Для имитации диалога часто используется форма вопросительного высказывания, которое не обращено к читателю напрямую. Особенно эффектно этот способ используется в заключительной части текста аннотации: либо для того, чтобы заинтриговать адресата (Здесь наперёд известно всё - кроме одного: кто из играюицих в игру бессмертия - Актеры, а кто - Зритель?..), либо побудить его к предположению о том, как разрешится коллизия (Василисе предстоит ... разгадать самую важную тайну в её жизни. Справится ли она с невероятной ответственностью, вдруг обрушивщейся на её юные плечи?).

С целью лишь намекнуть о художественном конфликте используются вопросно-ответные единства, причем ответная реплика может прогнозировать разрешение конфликта (Что будет? Кровь и ненависть. Любовь и политика...) или создавать неопределенность (Кто его выбрал на эту роль и с какой целью? Спросите чего попроще).

В косвенной форме диалогичности может имитироваться внутренняя речь героя. С её помощью эмотивный смысл презентуемого произведения перемещается в личное пространство мнений, ощущений и впечатлений будущего читателя. Так, в следующем примере эмоции страха и тревоги передаются от лица чётко обозначенного субъекта персонажа: Жизнь девочек в чужом для них городе, вдали от родньх людей, словно синее глубокое море... Как бь не оступиться, когда гуляешь вдоль прибрежных скал. Как бы тебя не накрыло холодным де- 
вятым валом. Остается только надежда. Герой и читатель охвачены одним и тем же чувством, и эта близость возникает благодаря «художественному» способу передачи сигнала эстетической информации адресату. Рекламный и художественный стили в аннотации в таких случаях вступают во взаимодействие благодаря смене дискурсивных рамок.

Таким образом, можно утверждать, что продвижение такого специфического объекта, как литературно-художественное издание, осуществляется в издательских аннотациях на основе организации особого - лингвокультурного пространства текста. Знаки вербального кода, презентующего это пространство, образуют культуремы, которые реализуют прагматико-эстетические функции создания образа, эмоционального впечатления, условий для интеллектуальной игры. Культурные единицы в рекламном тексте о книге выступают, во-первых, средством создания культурного (литературного) контекста и, во-вторых, инструментом для достижения маркетинговых целей: на основе художественного впечатления в них эффективно реализуется прагматическое намерение «агента» убедить читателя сигналами эстетической информации в нужности «товара». Интенции агента-продавца осуществляются только благодаря культурному посреднику, искусному автору аннотации, владеющему разнообразными способами создания стилистического эффекта, т.е. особым, «персуазивным письмом».

В лингвокультуремах на двух уровнях содержательного аспекта текста, фактологическом и интерпретационном, акцентируются достоинства следующих объектов: 1) писателя как непревзойденного мастера слова; 2) произведения как источника неповторимых читательских ощущений или бурных эмоций; 3) адресата с его разнообразными потребностями в чтении и художественном впечатлении, которые обязательно удовлетворит рекомендуемая книга. Эффект маркетинговой коммуникации в сфере литературно-художественной книги, т.е. персуазивность текста, создается следующими основными языковыми средствами вербализации этих достоинств: интертекстуальными, перифрастическими, эмотивными знаками, атрибутивами, аналогиями и способами диалогизации. Являясь сигналами эстетической информации, эти средства создают привлекательность книги, фокусируют внимание адресата, личную заинтересованность в ее чтении, передают ценностные смыслы и убеждают в целесообразности приобретения товара. 


\section{Литература}

1. Мароши В.В. Современный отечественный литературный процесс: роль института издателей. М. : МГУП, 2008. 140 с.

2. Ухова Л.В. «Продвигающий текст»: понятие, особенности, функции // Верхневолжский филологический вестник. 2018. № 3. С. 71-82.

3. Odih P. Advertising in Modern and Postmodern Times. Los Angeles ; London ; New Delhi ; Singapore : SAGE Publications Ltd., 2007. 232 p.

4. Борисова Е.Г. Маркетинговая лингвистика: направления и перспективы // Верхневолжский филологический вестник. 2016. № 4. С. 140-143.

5. Brown St. Writing Marketing. SAGE Publications Ltd., 2005. 272 p.

6. Holman D., Thorpe R. Management and Language. The Manager as a Practical Author. SAGE Publications Ltd., 2003. 196 p.

7. Richardson L. Writing Strategies. Reaching Diverse Audiences Qualitative Research Methods. 1990. Vol. 21.

8. Campbell M.C., Kirmani A. Consumer's use of persuasion knowledge: The effects of accessibility and cognitive capacity on perceptions of an influence agent // Journal of Consumer Research, 2000. № 27 (1). P. 69-83.

9. Reinhard M., Messner M. Explicit Persuasive Intent and Its Impact on Success at Persuasion - The Determining Roles of Attractiveness and Likeableness // Journal of Consumer Psychology. 2006. № 16 (3). P. 249-259.

10. Hasford J., Hardesty D.M., Kidwell B. More Than a Feeling: Emotional Contagion Effects in Persuasive Communication // Journal of Marketing Research. 2015. Vol. 52, № 6. P. 836-847. DOI: 10.1509/jmr.13.0081836

11. Основы государственной культурной политики. URL: http://base.garant.ru/ 70828330/86d100d0d858e8cc347da40ab84564e8/\#block_1000 (дата обращения: 4.02.2019).

12. Кара-Мурза Е.С. Современная русская реклама и ее внутренняя дифференциация // Медиалингвистика. 2015. № 4 (10). С. 19-34.

13. Рубакин H.A. Что такое библиологическая психология? URL: http://books.e-heritage.ru/book/10077325 (дата обращения: 11.01.2019).

14. Аверина Н.В. Реклама в книжной торговле. Современные стратегии и методы : автореф. дис. ... канд. филол. наук. СПб., 2011. 24 с.

15. Берштадт А.Б. Реклама книги в книговедении и издательском деле : автореф. дис. ... канд. филол. наук. М., 2009. 16 с.

16. Вишнякова М.Н.Специфика рекламы издательской продукции // Известия высших учебных заведений. Проблемы полиграфии и издательского дела. 2003. № 1. C. $102-108$.

17. Морева А.Н. Коммуникативные стратегии и тактики в медиажанре литературной рецензии (на материале «Литературной газеты») : автореф. дис. ... канд. филол. наук. Н. Новгород, 2016. 22 с.

18. Передний Д.М. Реклама книги: модификации и тенденции развития : автореф. дис. ... канд. филол. наук. М., 2005. 20 с. 
19. Иншакова Н.Г. Рекламный текст: редакторский взгляд. М. : Медиа-Мир, 2007. $286 \mathrm{c}$.

20. Stuhlfaut M.W., Vanden Bergh B.G. Creativity is...: A metaphoric model of the creative thought process // Journal of Marketing Communications. 2014. Vol. 20. P. 383-396.

21. Maguire J.S., Matthews J. The Cultural Intermediaries Reader. 2013. 256 p.

22. Бурдье П. Поле литературы. URL: http://bourdieu.name/content/burde-poleliteratury (дата обращения: 7.02.2019).

23. Слышкин Г.Г. От текста к символу: Лингвокультурные концепты прецедентных текстов в сознании и дискурсе. М. : Academia, 2000. 128 с.

24. Колесникова О.И. Креативные способы осмысления современной литературы в медийном дискурсе и прагматические условия их интерпретации читателем // Мир русского слова. 2015. № 2. С. 29-35.

25. Barnes J.L. Imaginary Engagement, Real-World Effects: Fiction, Emotion, and Social Cognition // Review of General Psychology. 2018. Vol. 22, № 2. P. 125-134.

\section{The Persuasive Text of Publisher's Annotations: A Linguocultural Aspect}

Tekst. Kniga. Knigoizdanie - Text. Book. Publishing, 2020, 22, pp. 125-138

DOI: $10.17223 / 23062061 / 22 / 8$

Olga I. Kolesnikova, Vyatka State University (Kirov, Russian Federation). E-mail: kolesn2006@yandex.ru

Keywords: publisher's annotation, persuasive text, linguacultureme, stylistic effect, pragmatic-aesthetic functions.

In the article, from the standpoint of a linguocultural approach, the means of creating persuasiveness in texts of publisher's annotations are considered. On the material of media resources (the largest specialized sites offering literary and artistic publications), the problem of promoting literary and artistic books and reading in the media is investigated. The author's focus is on verbalized cultural units - linguaculturemes. In annotations, they form a specific space of value-based meanings that affect the addressee of a book advertisement, stimulate readers' interest and form their expectations of vivid impressions from a beautiful promise. Linguaculturemes are found at two levels of the content of a text: factual and interpretative. The purpose of linguaculturemes is to accentuate the virtues of three objects: the writer, the work, and the addressee. At the factual level, information is transmitted about the place of the advertised book in the world of literature, its popularity among readers, about the plot, about the author of the work, his/her life, destiny, and creativity. At the interpretative level, the key idea of the work, its language and style are presented; the addressee is characterized; an anticipation of the pleasure of reading the advertised book is formed. All the mentioned components of the text are aimed at satisfying the reader's value needs and refer to aesthetic information, being an integral element of the annotation as a "promotion" text. The results of the analysis of persuasive annotation texts show that the means of verbalization of value-based meanings that can cause a stylistic effect are special signals of aes- 
thetic information. Their purpose is to perform pragmatic-aesthetic functions, which include the creation of an image, an emotional impression, and conditions for an intellectual game. The main means of creating a persuasive text of publisher's annotations that make up the linguaculturemes are identified and illustrated: intertextual, periphrastic, emotional signs, pragmatic and aesthetic attributes, semantic analogies and dialogization types. The author comes to the conclusion that linguaculturemes are not only a means of creating a literary context, but also a tool for achieving marketing goals: they effectively implement the pragmatic intention of the "agent" advertiser to convince the addressee (the potential reader/buyer) of the "product". The intentions of the seller agent are implemented only thanks to the cultural mediator knowing "persuasive writing", through which the book is attractive, the recipient's attention is focused on the merits of the work, personal interest in reading it is evoked, and value-based meanings are transmitted. The named features of the text of the annotation determine the effect of marketing communication in the field of literary and artistic books: the reader's conviction in the advisability of purchasing goods, which contributes to the promotion of the publisher's product.

\section{References}

1. Maroshi, V.V. (2008) Sovremennyy otechestvennyy literaturnyy protsess: rol' instituta izdateley [The modern Russian literary process: the role of publishing]. Moscow: MGUP.

2. Ukhova, L.B. (2018) "Prodvigayushchiy tekst": ponyatie, osobennosti, funktsii ["Promoting Text": concept, features, functions]. Verkhnevolzhskiy filologicheskiy vestnik - Verhnevolzhski Philological Bulletin. 3. pp. 71-82. (In Russian).

3. Odih, P. (2007) Advertising in Modern and Postmodern Times. Los Angeles; London; New Delhi; Singapore: SAGE Publications Ltd.

4. Borisova, E.G. (2016) Marketing linguistics: prospects and trends. Verkhnevolzhskiy filologicheskiy vestnik - Verhnevolzhski Philological Bulletin. 4. pp. 140-143. (In Russian).

5. Brown, St. (2005) Writing Marketing. SAGE Publications Ltd.

6. Holman, D. \& Thorpe, R. (2003) Management and Language. The Manager as a Practical Author. SAGE Publications Ltd.

7. Richardson, L. (1990) Writing Strategies. Reaching Diverse Audiences. SAGE Publications, Inc.

8. Campbell, M.C. \& Kirmani, A. (2000) Consumer's use of persuasion knowledge: The effects of accessibility and cognitive capacity on perceptions of an influence agent. Journal of Consumer Research. 27(1). pp. 69-83. DOI: 10.1016/j.jcps.2012.10.012

9. Reinhard, M. \& Messner, M. (2006) Explicit Persuasive Intent and Its Impact on Success at Persuasion - The Determining Roles of Attractiveness and Likeableness. Journal of Consumer Psychology. 16(3). pp. 249-259. DOI: 10.1207/s15327663jcp1603_7

10. Hasford, J., Hardesty, D.M. \& Kidwell, B. (2015) More Than a Feeling: Emotional Contagion Effects in Persuasive Communication. Journal of Marketing Research. 52(6). pp. 836-847. DOI: 10.1509/jmr.13.0081836 
11. The Russian Federation. (n.d.) Osnovy gosudarstvennoy kul'turnoy politiki [Basics of the state cultural policy]. [Online] Available from: http://base.garant.ru/ 70828330/86d100d0d858e8cc347da40ab84564e8/\#block_1000. (Accessed: 10th February 2019 ).

12. Kara-Murza, E.S. (2015) Modern Russian advertising and its inner differentiation. Medialingvistika - Media Linguistics. 4(10). pp. 19-34. (In Russian).

13. Rubakin, N.A. (n.d.) Chto takoe bibliologicheskaya psikhologiya? [What is bibliological psychology?] [Online] Available from: http://books.eheritage.ru/book/10077325. (Accessed: 17th February 2019).

14. Averina, N.V. (2011) Reklama v knizhnoy torgovle. Sovremennye strategii $i$ metody [Advertising in the book trade. Modern strategies and methods]. Abstract of Philology Cand. Diss. St. Petersburg.

15. Bershtadt, A.B. (2009) Reklama knigi v knigovedenii i izdatel'skom dele [Book Advertising in Bibliology and Publishing]. Abstract of Philology Cand. Diss. Moscow.

16. Vishnyakova, M.N. (2003) Spetsifika reklamy izdatel'skoy produktsii [The specifics of advertising publishing products]. Izvestiya vysshikh uchebnykh zavedeniy. Problemy poligrafii i izdatel'skogo dela. 1. pp. 102-108.

17. Moreva, A.N. (2016) Kommunikativnye strategii i taktiki v mediazhanre literaturnoy retsenzii (na materiale "Literaturnoy gazety") [Communicative strategies and tactics in the media genre of literary review (a case study of "Literaturnaya Gazeta")]. Abstract of Philology Cand. Diss. Nizhny Novgorod.

18. Peredniy, D.M. (2005) Reklama knigi: modifikatsii i tendentsii razvitiya [Book Advertising: Modifications and Development Trends]. Abstract of Philology Cand. Diss. Moscow.

19. Inshakova, N.G. (2007) Reklamnyy tekst: redaktorskiy vzglyad [Promotional text: the editorial perspective]. Moscow: Media-Mir.

20. Stuhlfaut, M.W. \& Vanden Bergh, B.G. (2014) Creativity is ...: A metaphoric model of the creative thought process. Journal of Marketing Communications. 20. pp. 383-396. DOI: 10.1080/13527266.2012.710644

21. Maguire, J.S. \& Matthews, J. (eds) (2013) The Cultural Intermediaries Reader. Sage Publishing. DOI: 10.4135/9781473912281

22. Bourdieu, P. (n.d.) Pole literatury [Field of Literature]. [Online] Available from: http://bourdieu.name/content/ burde-pole-literatury. (Accessed: 7th February 2019).

23. Slyshkin, G.G. (2000) Ot teksta k simvolu: Lingvokul'turnye kontsepty pretsedentnykh tekstov $v$ soznanii $i$ diskurse [From text to symbol: Linguocultural concepts of precedent texts in consciousness and discourse]. Moscow: Academia.

24. Kolesnikova, O.I. (2015) Creative Ways of Understanding of Modern Literature in Media Discourse and Pragmatic Conditions of a Reader's Interpretation. Mir russkogo slova - The World of Russian Word. 2. pp. 29-35. (In Russian).

25. Barnes, J.L. (2018) Imaginary Engagement, Real-World Effects: Fiction, Emotion, and Social Cognition. Review of General Psychology. 22(2). pp. 125-134. DOI: $10.1037 /$ gpr0000124 